Original Research Article

\title{
Quality of multiple choice questions in undergraduate pharmacology assessments in a teaching hospital of Kerala, India: an item analysis
}

\author{
Manju K. Nair*, Dawnji S. R.
}

Department of Pharmacology, Government Medical College, Thiruvananthapuram, Kerala, India

Received: 20 April 2017 Accepted: 25 April 2017

*Correspondence to:

Dr. Manju K. Nair,

Email:

manjusunjith@gmail.com

Copyright: (C) the author(s), publisher and licensee Medip Academy. This is an openaccess article distributed under the terms of the Creative Commons Attribution NonCommercial License, which permits unrestricted noncommercial use, distribution, and reproduction in any medium, provided the original work is properly cited.

\begin{abstract}
Background: Carefully constructed, high quality multiple choice questions can serve as effective tools to improve standard of teaching. This item analysis was performed to find the difficulty index, discrimination index and number of non functional distractors in single best response type questions.

Methods: 40 single best response type questions with four options, each carrying one mark for the correct response, was taken for item analysis. There was no negative marking. The maximum marks was 40 . Based on the scores, the evaluated answer scripts were arranged with the highest score on top and the least score at the bottom. Only the upper third and lower third were included. The response to each item was entered in Microsoft excel 2010. Difficulty index, Discrimination index and number of non functional distractors per item were calculated.

Results: 40 multiple choice questions and 120 distractors were analysed in this study. $72.5 \%$ items were good with a difficulty index between 30\%-70\%. $25 \%$ items were difficult and $2.5 \%$ items were easy. $27.5 \%$ items showed excellent discrimination between high scoring and low scoring students. One item had a negative discrimination index $(-0.1)$. There were 9 items with non functional distractors.

Conclusions: This study emphasises the need for improving the quality of multiple choice questions. Hence repeated evaluation by item analysis and modification of non functional distractors may be performed to enhance standard of teaching in Pharmacology.
\end{abstract}

Keywords: Difficulty index, Discrimination index, Distractors, High scoring, Item

\section{INTRODUCTION}

Systematic evaluation of student performance should be done regularly to improve student scores. Cognitive, affective and psychomotor domains of a student should be evaluated in the process. The cognitive domain can be assessed through different approaches like pen and paper based written examination, viva voce etc. Multiple choice questions (MCQs) are one of the common written test formats employed because questions can be set from a wide range of topics and they are easy to score too. ${ }^{1-4}$ However, there is always a chance for guessing and failure to credit knowledge which can reduce the validity of these tests. ${ }^{5}$ Hence, MCQs of high quality should be used so that students can put in a higher level of cognitive processing to answer them. ${ }^{6}$ Carefully constructed MCQs help in assessing higher order thinking skills. ${ }^{7-9}$ They also help in sampling broad domains of knowledge effectively and reliably. MCQs, therefore, can serve as an effective tool to assess student performance.

Quality of multiple choice questions can be found out using item analysis. It is a process which examines student's responses to individual test items, to assess the quality of items and the test as a whole. In addition to the quality of items, MCQ constructional skill of the examiner and poor items needing revision or deletion can also be recognised. ${ }^{7}$ It can also serve as an effective feedback tool to improve the standard of teaching. The difficulty index and the discrimination index can be computed doing an item analysis. Functionality of a distractor in an item can also be identified. ${ }^{7,10,11}$ 
The difficulty index refers to the difficulty level of the respondents to identify the correct alternative among the available distractors and is indicated by the percentage of test population giving the correct answer for an item. Higher the difficulty index, the easier is the item. ${ }^{10,11}$ The discrimination index helps to identify the ability of an item to discriminate the high performers from low performers. The distractors offered in MCQ tests are also relevant because a distractor that is not opted by any of the test takers reduces the number of alternatives and increases the chances of guessing an item correctly. ${ }^{3,12}$ This study was done to get an idea about the quality of multiple choice question type examination conducted for dental students in pharmacology by determining the difficulty index, discrimination index and number of non functional distractors in the test items and thereby improve the question setting skills of the evaluator and the standard of teaching in Pharmacology.

\section{METHODS}

Short tests including few topics are routinely conducted for dental students in Pharmacology. One such short test of multiple choice question type was randomly picked up for item analysis. There were 40 single best response type questions with four options, one option being the key and other three being the distractors. One mark was allotted for each correct response. There was no negative marking. 50 minutes was the time allotted for the completion of the test. There were thirty evaluated answer scripts. Based on the scores, they were arranged in a descending fashion with the highest score on top and the least score at the bottom. Then they were divided into three groups. The upper third and lower third were included in the study and designated as high scoring group and low scoring group respectively. The middle third (10 answer scripts) was excluded from the study. The responses chosen by each student for every question was entered in Microsoft excel 2010. Difficulty index and Discrimination index was calculated.120 distractors were also analysed to find out the frequency with which they were opted by each student and the number of non functional distractors in each item was assessed.

Difficulty index $=[(\mathrm{H}+\mathrm{L}) / \mathrm{N}] \mathrm{x} 100$ [where $\mathrm{H}=\mathrm{Number}$ of correct answers in high group, $\mathrm{L}=$ Number of correct answers in low group, $\mathrm{N}=$ total number of students]. ${ }^{7,10} \mathrm{It}$ denotes the percentage of students who have chosen the correct option. Higher the difficulty index, easier is the item. It ranges from $0-100 \%$. It was graded as follows: ${ }^{7}$

- $0-29 \%$ - Difficult

- 30-70\%- Good

- 71-100\% - Easy

\section{Discrimination index}

$[(\mathrm{H}-\mathrm{L}) / \mathrm{N}] \times 2$ [where $\mathrm{H}=$ Number of correct answers in high group, $\mathrm{L}=$ Number of correct answers in low group, $\mathrm{N}=$ total number of students]. ${ }^{7,10}$ It is the ability of an item to discriminate between high scorers and low scorers. It ranges from 0 to 1 . Lower scores indicate poor discriminative capacity of the item. It was graded as follows: ${ }^{7}$

- Less than 0 or negative - Very poor

- 0-0.19 - Poor

- 0.2 - 0.29 - Acceptable

- 0.3 - 0.39 - Good

- More than or equal to 0.4 - Excellent

Number of Non functional distractors per item: Any distractor that was opted by less than $5 \%$ examinees were taken as non functional. ${ }^{11}$

\section{RESULTS}

40 multiple choice questions with a total of 120 distractors were analysed in this study. Total number of students were 20, 10 each in high and low scoring group respectively. Maximum marks for the test was 40 . The scores for the test ranged from 5 to 27 marks.72.5\% of the questions had a difficulty index ranging between 30 $70 \%$. The difficulty index was less than $30 \%$ for $25 \%$ items and $2.5 \%$ of the questions were easy as they had a difficulty index more than $70 \%$. Mean \pm SD for difficulty index was 40.13 \pm 18.027 (Table 1).

\section{Table 1: Distribution of items in relation to difficulty index.}

\begin{tabular}{|ll|l}
$\begin{array}{l}\text { Grading of } \\
\text { Difficulty index }\end{array}$ & $\begin{array}{l}\text { Number of } \\
\text { items, } \mathbf{n}(\%)\end{array}$ & Mean \pm SD \\
\cline { 1 - 2 } $0-29 \%$ & $10(25 \%)$ & \multirow{2}{*}{$40.13 \pm 18.027$} \\
\hline $30-70 \%$ & $29(72.5 \%)$ & \\
\cline { 1 - 2 } $70-100 \%$ & $1(2.5 \%)$ & \\
\cline { 1 - 2 } Total & $40(100 \%)$ &
\end{tabular}

Table 2: Distribution of items in relation to discrimination index.

\begin{tabular}{|ll|l}
$\begin{array}{l}\text { Grading of } \\
\text { discrimination } \\
\text { index }\end{array}$ & $\begin{array}{l}\text { Number of items, } \\
\mathbf{n}(\%)\end{array}$ & \multirow{2}{*}{$0.268 \pm 0.2177$} \\
\hline$<0$ or negative & $1(2.5 \%)$ \\
\hline $0-0.19$ & $11(27.5 \%)$ \\
\hline $0.2-0.29$ & $9(22.5 \%)$ \\
\hline $0.3-0.39$ & $8(20 \%)$ \\
\hline$\geq 0.4$ & $11(27.5 \%)$ \\
\hline Total & $40(100 \%)$ \\
\hline
\end{tabular}

Discrimination index was poor in $27.5 \%$ items, acceptable in $22.5 \%$ items and good in $20 \%$ items. $27.5 \%$ of the items showed excellent discrimination between high scoring and low scoring students. One item had a negative discrimination index (-0.1). Mean \pm SD for discrimination index was $0.268 \pm 0.2177$ (Table 2). All the distractors were functioning and effective in 31 items. However, non functional distractors were detected in 9 
items. 1 non functional distractor was present in 7 items each. Two items contained 2 non functional distractors each (Table 3).

Table 3: Number of items in relation to Non functional distractors.

\begin{tabular}{|ll|}
$\begin{array}{l}\text { Number of Non functional } \\
\text { distractors / item }\end{array}$ & Number of items \\
\hline 0 & 31 \\
\hline 1 & 7 \\
\hline 2 & 2 \\
\hline
\end{tabular}

\section{DISCUSSION}

In this study, the item analysis of multiple choice questions was done to evaluate the difficulty index and discrimination index of 40 items. It was seen that $72.5 \%$ items had good difficulty index (30\%-70\%). The mean \pm SD for difficulty index was $40.13 \pm 18.027$. This shows that majority of the questions were in the acceptable range i.e. neither too easy nor too difficult. 10 items were difficult and one item was easy for the students. The easy item can be framed in the beginning of the question paper to boost the confidence of the students. In another study conducted on 488 items, 56.96\% items had a difficulty index ranging between 30\%-70\%, $23.3 \%$ items were easy and $5.53 \%$ were difficult. ${ }^{10}$

11 items $(27.5 \%)$ could excellently discriminate between high scoring and low scoring students as the discrimination index was more than 0.4. Eight items (20\%) had a discrimination index ranging between 0.3 0.39 which was good.

However, $27.5 \%$ items had poor discriminating capacity. These questions should be looked into, revised or discarded. The discrimination index was negative in one question. This is not an ideal situation. This might be because of low scorers opting for the right option more than the high scorers. The high scorers would have thought more on the question and opted for a wrong answer. This item should be looked into for confusing words or wrong key and discarded. In a study in Karnataka, 20.49\% items had excellent discriminating capacity. ${ }^{10} 15.77 \%$ items were good with a discrimination index ranging between 0.3-0.39. However, 31.96\% items poorly discriminated high scorers from low scorers.

A total of 120 distractors were analysed in this study. There were no non functional distractors in 31 items. However, 9 items had non functional distractors. They should be analysed and emphasis should be laid on the right option during regular classes so that the students can remember it in future.

\section{CONCLUSION}

This study also emphasises the need for improvement in quality of MCQs. Repeated evaluation of multiple choice questions by item analysis and modification of non functional distractors can improve the quality of MCQs. Further, attending faculty development programs also can help the faculties to construct quality MCQs which will help as an effective tool to enhance the standard of teaching in pharmacology.

\section{Funding: No funding sources \\ Conflict of interest: None declared \\ Ethical approval: Not required}

\section{REFERENCES}

1. Bailey PH, Mossey S, Moroso S, Cloutier JD, Love A. Implications of multiple-choice testing in nursing education. Nurse Educ Today. 2012;32(6):e 40-4.

2. Collins J. Education techniques for lifelong learning: writing multiple-choice questions for continuing medical education activities and self-assessment modules. Radiographics. 2006;26 (2):543-51.

3. Sayyah M, Vakili Z, Alavi NM, Bigdeli M, Soleymani A, Assarian M. An Item Analysis of Written Multiple-Choice Questions: Kashan University of Medical Sciences. Nurs Midwifery Stud. 2012;1(2):83-7.

4. Kuechler WL, Simkin MG. How well do multiple choice tests evaluate student understanding in computer programming classes? J Inf Syst Educ. 2003;14(4):389-400.

5. Lau PNK, Lau SH, Hong KS, Usop H. Guessing, Partial Knowledge, and Misconceptions in MultipleChoice Tests. Educ Tech Soc. 2011;14 (4):99-110.

6. Clifton SL, Schriner CL. Assessing the quality of multiple-choice test items. Nurse Educ. 2010;35(1):12-6.

7. Shete AN, Kausar A, Lakhkar K, Khan ST. Item analysis: An evaluation of multiple choice questions in Physiology examination. J Contemp Med Edu. 2015;3(3):106-9.

8. Norman G. The program for educational development. Evaluation Methods A Resource Handbook, Multiple Choice Questions.Ch. 4.1. Hamilton, Canada: McMaster University; 1995:4754.4.

9. Peitzman SJ, Nieman LZ, Gracely EJ. Comparison of fact-recall with higher-order questions in multiplechoice examinations as predictors of clinical performance of medical students. Acad Med. 1990;65:S59-60.

10. Karkal YR, Kundapur GS. Item analysis of multiple choice questions of undergraduate pharmacology examinations in an International Medical School in India. Journal of Dr. NTR University of Health Sciences. 2016;5(3):183-6.

11. Gajjar S, Sharma R, Kumar P, Rana M. Item and test analysis to identify quality multiple choice questions (MCQs) from an assessment of medical students of Ahmedabad, Gujarat. Indian J Community Med. 2014 Jan-Mar;39(1):17-20. 
12. Hingorjo MR, Jaleel F. Analysis of one best MCQs: the difficulty index, discrimination index and distractor efficiency. J Pak Med Assoc. 2012;62(2):142-7.
Cite this article as: Nair MK, Dawnji SR. Quality of multiple choice questions in undergraduate pharmacology assessments in a teaching hospital of Kerala, India: an item analysis. Int J Basic Clin Pharmacol 2017;6:1265-8. 